Physical development of children is a marker of adequacy of nutrition, and affects adaptation, severity of pathological processes, rate of recovery, effectiveness of therapy, terms of hospitalization. Not enough teaching time is devoted to the study and training of nutrition status assessment skills in various ways.

The skill of evaluation of physical development (FR) and nuthritical status (NS) was worked out on the questionnaire data of specific patients. The results of the programme WHO Antro assessment, the centyl tables and the impedance data were compared in 101 patients with eating disorders (54 boys), from 2 m.o to 17 y.o (average 8.5 y.o) Malnutrition $30 \%$, severe malnutrition $-6 \%$ cases. Obesity revealed $39 \%$ kids. The results of the WHO Antro assessment, the percentile tables and the impedance data were compared. Direct correlation links between the child 's percentile weight corridor, the WHO Antro (z-score), and the percentage of deficiency or excess of fat and active cell mass are obtained $(p=0.05)$. The child 's percentile growth corridor and body mass index also correlates with the growth $\mathrm{z}^{-}$scor, fat, and active cell mass percent according to body impedance $(p=0.05)$.

The skill of assessing physical development and nuthritical status by students can be formed using simulation technologies. Physical development, as well as the nuthritical status of the child, can be investigated by the WHO Antro program using a computer application, or by using technologically complex equipment - impedance, or manually - with the help of centyl tables.

Deviations of nutritive status from physiological norm are determined by all proposed methods.

\section{PREVENTIVE HEALTH CARE OF CHILDREN IN CROATIA DURING COVID-19 EPIDEMIC}

Željka Draušnik*, Đurða Španović, Urelija Rodin, Alojz Radman. Croatian Institute of Public Health

10.1136/archdischild-2021-europaediatrics.469

To determine the impact of the COVID-19 epidemic on preventive health care visits and vacciantions in pediatrician practises in primary health care in Croatia.

Data about preventive health care visits and vacciantions of infants and preschool children in pediatrician practises in primary health care in Croatia were extracted from the Central Health Information System of the Republic of Croatia and comparison of 2019 and 2020 data was made, respectively month by month. We analized data only for infants and preschool children, from 0 to 6 years old.

In total, during 2019, 268,556 preventive health care visits of infants and preschool children were recorded compared to 252,690 during the 2020, which is decline of $5.9 \%$. The biggest decline, 42.6\%, was recorded during the March 2020, but with notable increase in the following months which almost overturned the impact of the initial decline. New decline in the visits was seen during the November, but far smaller than during the begining of epidemic. Regarding vacciantions, during the 2019, 238,799 vaccinations were recorded to be administred, compared to 262,157 during the 2020 , which is increase of $9,8 \%$. The biggest decline was also seen during the March, 26.1\%.

Begining of COVID-19 epidemic in Croatia caused a major decline in the number of preventive health care visits and vaccinations already during March 2020. It was probably direct consequence of 'lockdown'and parental fear of going to a health facility. Negligible is also the earthquake that hit Zagreb and surroundings in mid-March. Joint and rapid response of together primary pediatricians and Croatian Institute of Public Health with the thrust of the parents, manage to stop the decline of the numbers and even to increase the numbers in the following months. A second round of the decline in preventivne health care visits, during the late autumn and the begining of winter, was probably result of increase in the number of SARS-CoV- 2 positive people, including children, self-isolations and possible delay of vaccination after child is recovered from COVID-19.

However, this favorable situation with frequency of preventive health care visits and vaccinations in Croatia during the COVID-19 epidemic gives us hope that in the future Croatia will not face vaccine-preventable communicable diseases outbreak, as some countries expect and once more emphasizes the importance of the pediatricians in the primary health care for the well-being of infants and preschool children.

\section{PARENTAL ASSESSMENT ON NEURODEVELOPMENTAL OUTCOMES IN CHILDREN BORN LATE PRETERM AT 2, 3, 5 AND 8 YEARS OLD}

Diana Simão Raimundo*, Joana Mendão Carreira, João Vasco, Eulália Viveiros. Hospital do Divino Espirito Santo, Ponta Delgada, Portugal

10.1136/archdischild-2021-europaediatrics. 470

In recent years, there has been growing evidence that children born late preterm (LPT) (34 0/7 - 36 6/7 weeks' gestation) are at higher risk for multiple morbidities during childhood and even adulthood. We aimed to evaluate late neurodevelopment in children born LPT at ages of 2, 3, 5 and 8 years old (у.o).

All LPT born in 2012, 2015, 2017 and 2018 in a Portuguese island region were selected from clinical records and a questionnaire was applied to their parents. Descriptive statistics analysis was performed.

Response rate was $67,0 \%$ (total $=207 ; 2$ y.o. $n=63 ; 3$ y.o. $\mathrm{n}=62 ; 5$ y.o. $\mathrm{n}=53 ; 8$ y.o $\mathrm{n}=29$ ). Within LPT group, none of the evaluated outcomes recorded statistically significant differences between gestational ages. Visual and hearing impairment increased with age, until $55,2 \%$ and $26,0 \%$, respectively, at 8 y.o; this suggests that these potential problems may go unnoticed in the first years of life, becoming evident at school age. About $1 / 5$ of the LPT presented difficulties in language/speech by 2 and 3 y.o., and it remained high at 5 years $(11,3 \%)$, but with a lower rate at 8 years $(3,4 \%)$. Warning signs for emotional/behavioral disturbance were reported in about $10 \%$ of 5 and 8 y.o., using the parameters recommended by the National Program for Child and Youth Health. Diagnosed attention deficit hyperactivity disorder (ADHD) was found in $6,9 \%$ of children aged 8 , coincident with the prevalence estimated worldwide. However, 17,2\% of all 8 y.o. LPT showed warning signs on Conners' Parent Rating Scale, suggesting this clinical entity may be underdiagnosed or that parental reports may indicate behavior dysfunctionality despite criteria for attention deficit hyperactivity disorder (ADHD) are not met. School learning difficulties with grade retention were reported in $17,2 \%$ of the 8 y.o. LPT children, much higher than the national mean retention rate in the 2 nd grade $(5,8 \%)$. These 
results are in agreement with recent studies that report higher borderline intellectual functioning and lower IQ scores in school-aged LPT.

Parental assessment on LPT showed increasing visual and hearing impairment until school-age, difficulties in language/ speech until 5y.o., a high rate of grade retention, increased signs of childhood behavior problems, but not higher rates of ADHD. LPT's parents should be informed about the possible late complications. Special attention and follow-up must be paid to LPT from the beginning for timely detection and intervention in capacities that can impair neurodevelopment, hearing-speech-language and learning capability of these children.

\section{CLINICAL AND PREVENTIVE EFFICACY OF PHYTOPREPARATIONS IN PRE-SCHOOL CHILDREN WITH ADENOTONSILLAR PATHOLOGY}

Vera Vavilova*, Alexsander Vavilov, Asya Cherkaeva, Irina Nechaeva, Vitalyi Tiuliukin. Kemerovo State Medical University

\subsection{6/archdischild-2021-europaediatrics.471}

Assessing efficacy of Tonsilgon $\mathrm{N}$ in pre-school children as an etiotropic drug in complex therapy of adenotonsillar pathology at the rehabilitation stage.

Within the period from 2011 to 2015, 1,076 children (aged from 2 to 5 years) with a history of pathology of nasopharyngeal and palatine tonsils in $100 \%$ of cases were reviewed. Pre-school children were given Tonsilgon $\mathrm{N}$ phytopreparation in the form of drops in age-specific doses within 30 days.

The control group included 200 children. The phytopreparation efficacy was analyzed before and after the preventive therapy.

A year prior to the preventive therapy, degree II nasopharyngeal tonsil hypertrophy complicated by adenoiditis was noted in $71.3 \%$ of children in the treatment group and in $74.5 \%$ of children in the control group. Degree III nasopharyngeal tonsil hypertrophy made $28.7 \%$ and $25.5 \%$, respectively. A year after the rehabilitation therapy, only $32.9 \%$ of patients in the treatment group did not show improvement in the clinical presentation. Symptoms of adenoiditis were practically relieved in half of the patients, nasal breathing was restored in $95.8 \%$ of patients, the size of a nasopharyngeal tonsil was reduced from degree II to degree I in $64.9 \%$ of patients.

Normalization of the rhinoscopy presentation was noted in $82 \%$ of patients, $77.9 \%$ of patients showed reduction of the ARI rate from 5-8 to 2-3 times a year. Endoscopic control confirmed reduction of size of both nasopharyngeal and palatine tonsils in $64.9 \%$ of patients. The hypertrophy degree of nasopharyngeal and palatine tonsils in pre-school children not receiving Tonsilgon $\mathrm{N}$ phytopreparation did not show any change. In addition, hypertrophy demonstrated increase from $74.5 \%$ to $83 \%$ over time.

Prospective study of children receiving Tonsilgon $\mathrm{N}$ as a rehabilitation method demonstrated its efficacy on immune development of the respiratory tract. The obtained data allow us to recommend Tonsilgon $\mathrm{N}$ to be included in programs of immune rehabilitation and prevention of exacerbation of adenotonsillar pathology.

\section{2 EUROPEAN ONLINE SEARCH PATTERNS OF FLU VACCINATION DURING THE COVID-19 PANDEMIC}

Inês Silva Costa*, Madalena Meira Nisa, Lígia M Ferreira. Pediatrics Department, Centro Hospitalar Tondela-Viseu EPE, Portugal

10.1136/archdischild-2021-europaediatrics.472

Google Trends (GT) is an online data tool that measures Relative Search Volume (RSV). In medical settings, it has proven to be associated with patient's perceptions and even changes in search for medical care. To identify a possible increase in online search patterns about flu vaccination during the COVID-19 pandemic, we conducted a GT analysis in a group of European countries.

A GT analysis with the GT topic 'flu vaccine' was performed between 2016 and 2020. Retrieved RSV was represented between 0 and 100 (highest interest in the query). Two groups of countries were selected, according to the reported incidence rate of COVID-19 by the European Center for Disease Prevention and Control, between week 37 and 41 of 2020, in children under 15 years (highest incidence: Belgium, Czech Republic, Spain, Portugal and Denmark; lowest incidence: Poland, Sweden, Norway, Finland and Greece).

Flu vaccination season (FVS) is considered to be, yearly, between week 38 and 44 and COVID-19 pandemic (CVP) from week 4 of 2020, as the first reported case in Europe was diagnosed.

Median RSV about 'flu vaccine', before the COVID-19 pandemic, varied between 0 (Czech Republic and Portugal) and 4 (Belgium and Poland) outside the FVS and between 0 (Czech Republic) and 31 (Greece) during the FVS.

As the CVP settled, the online search increased significantly, outside the FVS in every country $(\mathrm{p}<0.05)$, except in Czech Republic $(p=0.216)$. During the FVS, the search patterns also increased in every studied country $(p<0.05)$, but not in Finland $(\mathrm{p}=0.214)$.

As to the percentage of increase in RVS (during the FVS), before and during the CVP, the top 5 countries were, in order: Czech Republic (>5200\%), Spain (484,6\%), Poland (400,0\%), Denmark (311,8\%) and Portugal (280\%). Belgium placed ninth in increase rate, with $149,0 \%$.

Flu vaccination is one of the most acknowledged public health measures, and its online search interest usually peaks as the FVS begins every year.

During the FVS in 2020, 4 out of the 5 countries with the highest incidence of COVID-19 in children $<15$ years ranked in the top 5 studied countries with the highest increase in online search of flu vaccine.

\section{VALIDITY OF THE AGES AND STAGES QUESTIONNAIRE FOR DETECTING LATER BELOW AVERAGE COGNITIVE FUNCTION}

${ }^{1}$ Andrea Bowe*, ${ }^{2}$ Jonathan Hourihane, ${ }^{3}$ Anthony Staines, ${ }^{4}$ Deirdre Murray. ${ }^{1}$ INFANT Research Centre, Paediatric Academic Unit, Cork University Hospital, Wilton, Cork, Ireland; ${ }^{2}$ INFANT Research Centre, Cork, Ireland; Paediatrics, Royal College of Surgeons in Ireland, Dublin, Ireland; ${ }^{3}$ School of Nursing, Psychotherapy and Community Health, Dublin City University, Dublin, Ireland; " INFANT Research Centre, Cork, Ireland; Department of Paediatrics and Child Health, Cork University Maternity Hospital, Wilton, Cork, Ireland

10.1136/archdischild-2021-europaediatrics.473 